\title{
NOTE
}

\section{A method for retrieval of anchored stomach probes from seabirds}

\author{
Rory P. Wilson*, Mandy A. M. Kierspel \\ Institut für Meereskunde, Düsternbrooker Weg 20, D-24105 Kiel, Germany
}

\begin{abstract}
In an attempt to hinder regurgitation of stomach probes in free-living endotherms, the use of spring-based anchors has been suggested although the difficulty of subsequent extraction of the probes from the stomachs has been acknowledged. We present a modification in the construction of such anchored probes so that units can be easily retrieved using a magnetic grab system. The system was tested on 8 free-living Magellanic Penguins Spheniscus magellanicus in Argentina and was found to be quick and easy to use, involving minimal stress to the study animal while being $100 \%$ successful
\end{abstract}

KEY WORDS: Stomach probes - Spheniscus magellanicus

In a recent publication, Wilson et al. (1998) describe how stomach probes, used to determine feeding and digestive activity of free-living seabirds (Wilson et al. 1992, 1995, Gales \& Renouf 1993, Grémillet \& Plös 1994, Peters 1997 a, b), can be modified so that the incidence of spontaneous regurgitation is reduced. The modification involves the use of a soft, flexible spring crown attached to the titanium housing of the logging unit. The efficacy of the retention mechanism is such that recovery of the devices cannot be effected by simple stomach pumping (Wilson 1984), as was suggested for earlier, non-anchored units (Wilson et al. 1992). To this end Wilson et al. (1998) suggested the use of a rather complex loop system for device retrieval, but advocated extreme care since damage to the bird was possible. These authors further recommended that workers consider using a magnet retrieval system before resorting to the loop, although within the time frame of their work Wilson et al. (1998) could not test such a magnet system on free-living birds.

\footnotetext{
•E-mail: rwilson@ifm.uni-kiel.de
}

In this note we present the results of trials using a magnet-based system for retrieving anchored stomach probes.

Field work was conducted on Magellanic Penguins Spheniscus magellanicus at 3 breeding colonies, Punta Norte $\left(63^{\circ} 52^{\prime} \mathrm{W}, 42^{\circ} 05^{\prime} \mathrm{S}\right)$, Peninsula Valdés, Banco Cormoran (67 $\left.43^{\prime} \mathrm{W}, 49^{\circ} 17^{\prime} \mathrm{S}\right)$, San Julian, and Cabo Virgenes ( $\left.68^{\circ} 23^{\prime} \mathrm{W}, 52^{\circ} 21^{\prime} \mathrm{S}\right)$, Magellan Straits, all in Argentina, during November and December 1997. A total of 8 birds was equipped with stomach probes (the parameter to be monitored in this case being temperature), complete with spring retention system as described in Wilson et al. (1998). Briefly, the electronics was encased in a turned titanium housing, with a water-tight cap, measuring $91 \mathrm{~mm}$ long $\times 16 \mathrm{~mm}$ in diameter and weighing $33 \mathrm{~g}$. The spring retention system consisted of a crown of diameter $45 \mathrm{~mm}$ linked to one end of the housing by 4 spring struts, each $30 \mathrm{~mm}$ long. The external diameter of all springs was $5 \mathrm{~mm}$, wire thickness was $0.5 \mathrm{~mm}$ and there were ca 4 turns per $\mathrm{cm}$ length. Springs were made of special inert molybdenum steel alloy (see Wilson et al. 1998 for details). In addition, a magnet (neodinium boron Vacodym $335 \mathrm{WZ}, 11 \mathrm{~mm}$ diameter $\times 2 \mathrm{~mm}$, magnetized across the 2 main faces; Vacuumschmelze GmbH, Grüner Weg 37, D-63450 Hanau, Germany) was glued to the non-spring end of each unit using 2-component epoxy, before being coated with a thin layer of paint and a final, exterior layer of silicon rubber.

Birds tending chicks were caught at their nests at around mid-day and fed the stomach probes after the spring crown had been folded as described in Wilson et al. (1998). Birds were then left for a minimum of $24 \mathrm{~h}$ to allow them time to go to sea to complete at least one foraging trip for their chicks before regular nest checks were made to recover equipped individuals. When the birds returned they were recaptured and the presence 


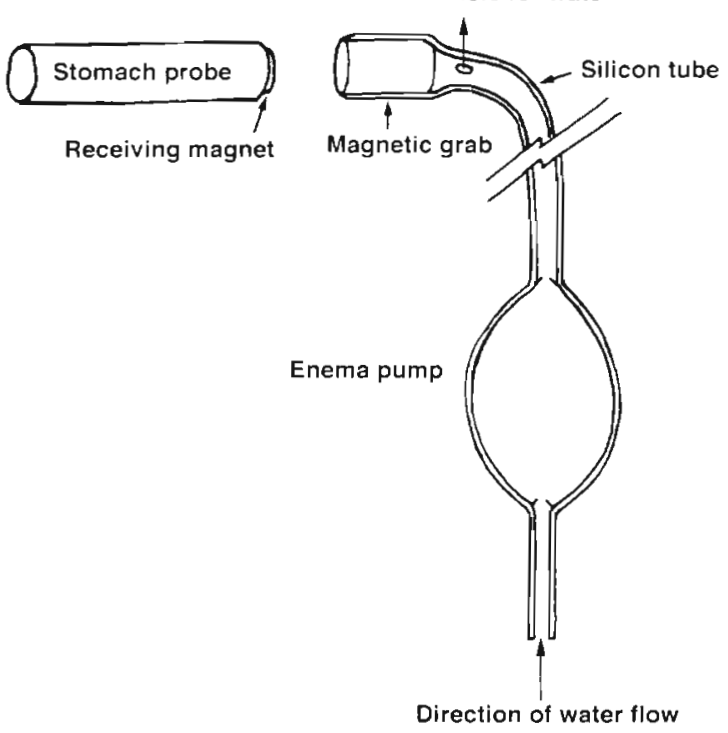

Fig. 1. Schematic diagram of the magnetic grab retrieval system presented in the text

of the stomach probe ascertained by use of a metal detector (Ebinger airport metal detection system EB 6067, Ebinger, Köln, Germany). Subsequently, we attempted to retrieve the units using a specially-developed magnetic grab. This consisted of a thin silicon tube (non-stretched external diameter $11 \mathrm{~mm}$, wall thickness $1.3 \mathrm{~mm}$, length $50 \mathrm{~cm}$ ) into one end of which 25 of the magnets described above were inserted as a single pack (bound together across their North-South faces). The magnetic pack was held in place by the elasticity of the silicon and lay flush with the cut end of the tubing. To facilitate swallowing, the tubing was rounded off around the end magnet. Finally, immediately posterior to the magnets, a small (5 mm diameter) hole was made in the silicon tubing and the nonmagnet end of the tubing connected to the output of a through-flow, bulb enema pump (Fig. 1).

To retrieve the stomach probes, the birds were held while the silicon tube, with the magnet end leading, was introduced slowly down the birds' throats. The magnet passed into the stomach without resistance and an audible click was usually heard (5 of 8 cases) as the magnetic pack in the grab system locked onto the magnet in the stomach probe housing. In an initial case we gently pulled the silicon tube back up the oesophagus but, when the spring retention system of the stomach probe met the narrowing at the stomachoesophageal junction, there was resistance and the grab system released (laboratory tests showed that the force needed to detach the magnetic grab from the stomach probe was of the order of $16 \mathrm{~N}$ ). We repeated the locking on and pulling process for a further 4 times before the spring could be pulled through the junction, whereupon the stomach probe was then pulled up and out of the oesophagus without problem. There was no sign of distress to the bird, other than that incurred during normal handling, but examination of the spring showed a small fleck of fresh blood in one place indicating that the stomach or oesophagus was likely to have been scratched during pulling. Thus, in all other cases, after the magnetic grab had locked onto the stomach probe, we introduced warm water into the birds's stomachs via the small hole in the silicon tube, and driven by the enema pump (ct. Wilson 1984) until water exited by the beak (Fig. 2). By this time all the birds had fully dilated the narrowing at the junction between stomach and oesophagus and the stomach probe could be pulled out using the magnetic grab without any resistance at all. The procedure was terminated by inverting the birds and removing any excess water as described for wet-offloading by Wilson (1984).

The stomach probes were inside the penguins for a mean period of $42 \mathrm{~h}$ (SD $14 \mathrm{~h}$ ), and the complete recovery of the units, from capture of the birds to their release at the nest site, took less than 4 min (typically 2 min). We checked the handled birds for periods of between 2 and $10 \mathrm{~d}$ subsequent to device retrieval and there was no apparent difference between them and other, non-equipped conspecifics.

We would highly recommend that researchers working with anchored stomach probes use the magnetic grab retrieval system presented here rather than the loop system presented in Wilson et al. (1998). The mag-
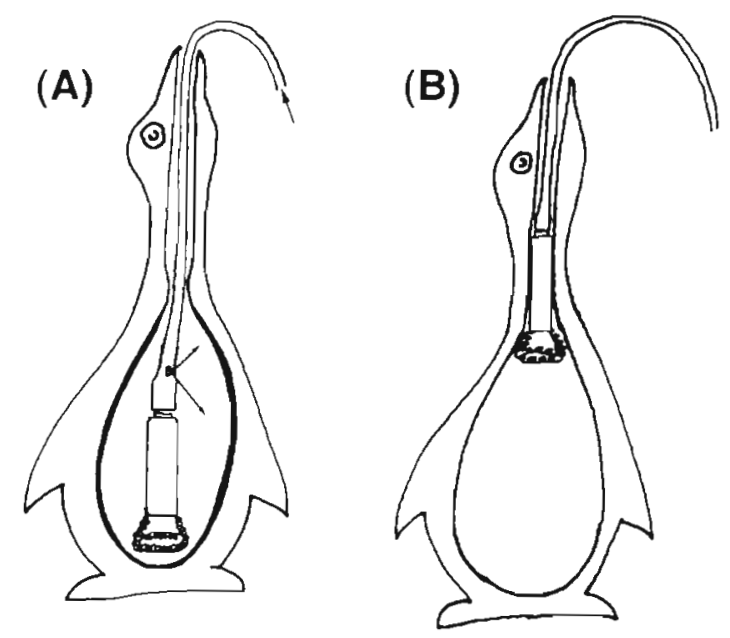

Fig. 2. Schematic diagram of the retrieval system in operation. (A) Water is pumped via the enema pump through the silicon tube to the bird's stomach. (B) This causes the stomach to fill up, eventually inducing the bird to dilate the stomach/ oesophageal junction so that the stomach logger can be removed 
nets in the grab automatically lock on to the logger, which eliminates any need for researchers to have to feel their way to the spring, as is necessary in the loop system. As such, retrieval of the units can be performed simply and easily, even by relatively inexperienced personnel.

We feel that gluing the magnet to the lid of the stomach probe is not ideal, although it was appropriate for our short-term purposes. Longer term deployment of stomach probes with externally glued magnets would presumably lead to the stomach acidity breaking down the glue, or the silicon covering of the magnet, and eventually the magnet itself. This problem can be easily overcome by ensuring that the magnet is placed inside the lid of the stomach probe housing while ensuring that the lid thickness at this point is minimal.

Acknowledgements. The study received financial support from the Deutsche Forschungsgemeinschaft (Wi 1023/2-1). We are grateful for logistic support to the Centro Patagonico, Pinocho Tours and the Consejo Agrario Provincial de la Provincia de Santa Cruz. We are particularly indebted to Carlos, Leonor, José and Nieves Cendron, Raul Clarke, Hector Gallelli, Sonia Laurenti, Gerrit Peters, Alejandro Scolaro and Jorge Upton for help in a multitude of ways. Grateful thanks

Editorial responsibility: Otto Kinne (Editor),

Oldendorf/Luhe, Germany are extended to Herr Reisert, Vacuumschmelze for magnetic expertise and for providing us with some of the world's most potent magnets

\section{LITERATURE CITED}

Gales R, Renouf D (1993) Detecting and measuring food and water intake in captive seals using temperature telemetry. J Wildl Manag 57:514-519

Grémillet D, Plös AL (1994) Use of temperature telemetry records for the calculation of daily food intake in cormorants. J Exp Biol 189:105-115

Peters G (1997a) A new device for monitoring gastric $\mathrm{pH}$ in free-ranging animals. Am J Physiol 273:G748-G753

Peters G (1997b) Die Regulation der Verdauungsprozesse bei Pinguinen (Spheniscidae). PhD thesis, Universität Kiel

Wilson RP (1984) A new improved stomach pump for penguins and other seabirds. J Field Orn 55:109-112

Wilson RP, Cooper J, Plötz J (1992) Can we determine when marine endotherms feed? A case study with seabirds. J Exp Biol 167:267-275

Wilson RP, Pütz K, Grémillet D, Culik BM, Kierspel M, Regel J, Bost CA, Lage J, Cooper J (1995) Reliability of stomach temperature changes in determining feeding characteristics of seabirds. J Exp Biol 1115-1135

Wilson RP, Peters G, Regel J, Grémillet D, Pütz K, Kierspel M, Weimerskirch H, Cooper J (1998) Short retention times of stomach temperature loggers in free-living seabirds; is there hope in the spring? Mar Biol 130:559-566

Submitted: January 16, 1998; Accepted: January 22, 1998 Proofs received from author(s): February 6, 1998 